\title{
Application of Thermography and Digital Image Correlation on the study of fatigue damage in fiber reinforced composites
}

by V. Dattoma, S. Giancane, R. Nobile, F.W. Panella

Dept. of Engineering of Innovation, University of Salento, Via per Monteroni 73100 Lecce, Italy, simone.giancane@unisalento.it

\begin{abstract}
This study explores the simultaneous use of two different full-field techniques (Digital Image Correlation and Thermography) to evaluate the fatigue damage status of glass fiber reinforced composites.

The damage phenomena are localized and not uniform and they are accompanied by higher strain and dissipated energy causing, under opportune conditions, local increase of temperature and important spatial gradients of temperature. Both these two aspect (strain and temperature gradients) were considered to identify and follow the damage evolution showing an interesting and reliable evaluation of fatigue behaviour and resistance of studied composites.
\end{abstract}

\section{Introduction}

High strength to weight ratio makes composites materials attractive for all the applications where light-weight and structural integrity are critical aspect. Moreover, the different resins employed made composites versatile also for that applications where the structures work in variable and severe environmental conditions just as the wind turbines. Despite the widespread use of composites there is not a definitive analytical model to be followed on a standardized procedure to predict their fatigue life or the behaviour in post-damage conditions. For these reasons non-perturbative and full-field techniques seem to have the better characteristics to be employed as investigation tool for the evaluation of the progressive damage into a material.

\section{Digital Image Correlation}

Digital Image Correlation is a pattern recognition technique that uses the correspondence between sub-images centred on the markers of a virtual grid superimposed on the first images [1]. Considering a batch of images, the first is taken as reference and a virtual grid is superimposed on it; opportune algorithms [2] allow to find the position of the markers of the grid for every image and to calculate the field of superficial displacements at the time which an image is referred to. The images must present a significant contrast to make the process work, so the specimens were prepared painting them with white varnish spread on a black background.

Starting from the maps of strain, Young's modulus (here indicated with E) and dissipated mechanical energy (here indicated with $\mathrm{H}$ ) were calculated for every complete cycle and for every marker by means of dedicated algorithms and opportunely elaborated routines in MATLAB language [3-4].

\section{Thermography}

It is well known that dissipative phenomena associated to plastic strain due to cyclic load are accompanied by an increase of temperature into the material. About fifteen years ago the researchers observed that a specimen under fatigue constant load can shows a typical temperature trend with three steps during its lifetime somehow related with its fatigue limit [5]. This approach can be applied only to those materials presenting an evident fatigue limit and do not allow gaining any information about the spatial distribution of damage. Differently, this work proposes to consider the temperature detected by an infrared camera as related to dissipation sources according to a thermo-mechanical framework. In that way, evaluations about spatial and in-time evolution of damage can be carried out and the results correlated and compared with the results obtained with DIC elaboration [8].

\section{REFERENCES}

[1] Sutton S., Wolters M.J., Peters W.H., Ranson W.F., McNeill S.R., "Determination of displacements using an improved digital correlation method”. Image Vision Comput., vol. 1(3), pp. 133-139, 1983.

[2] Lewis J.P. Fast Normalized Cross-Correlation. Industrial Light \& Magic, 2000. 
[3] Giancane S., Panella F.W., Dattoma V., "Characterization of fatigue damage in long fiber epoxy composite laminates". Int J Fatigue, vol. 32, pp. 46-53, 2010.

[4] Giancane S., Panella F.W., Nobile R., Dattoma V., "Fatigue damage evolution of fiber reinforced composites with digital image correlation analysis". Procedia Engineering 2 (Fatigue 2010), pp. 1037-1315, 2010.

[5] La Rosa G., Risitano A., "Thermographic methodology for rapid determination of the fatigue limit of materials and mechanical components". International Journal of Fatigue, vol. 22(1), pp. 65-73, 2000.

[6] Giancane S., Chrysochoos A., Dattoma V., Wattrisse B., "Deformation and dissipated energies for high cycle fatigue of 2024-T3 aluminium alloy”. Theoretical and Applied Fracture Mechanics, vol. 52, pp. 117-121, 2009. 